\title{
Success of medical management of tubal ectopic pregnancy with Methotrexate in a tertiary hospital in North India
}

\author{
Sunil K. Juneja, Kanupriya Jain*
}

Department of Obstetrics and Gynecology, Dayanand Medical College and Hospital, Ludhiana, Punjab, India

Received: 02 April 2018

Accepted: 02 May 2018

*Correspondence:

Dr. Kanupriya Jain,

E-mail: kanupj@gmail.com

Copyright: (C) the author(s), publisher and licensee Medip Academy. This is an open-access article distributed under the terms of the Creative Commons Attribution Non-Commercial License, which permits unrestricted non-commercial use, distribution, and reproduction in any medium, provided the original work is properly cited.

\begin{abstract}
Background: Unruptured ectopic pregnancy can be managed with surgery as well as systemic methotrexate. We aimed to study efficacy of medical management and factors affecting success in strictly selected patients.

Methods: It was a three-year prospective observational study. 171 patients with ectopic pregnancy were screened and those fulfilling the strict study criteria were given systemic methotrexate. The single dose regimen was followed. Patients were observed for side effects and signs of rupture. Serial measurement of HCG levels was done to determine success or failure. Various factors were studied which had potential bearing on results.

Results: Thirty-one patients received methotrexate. We had an overall success rate of $93 \%$. Two of the participants had surgery due to failure. No major side effects were observed.

Conclusions: Carefully selected patients of unruptured ectopic pregnancy can be safely and successfully treated with systemic methotrexate.
\end{abstract}

Keywords: Ectopic pregnancy, Medical management, Methotrexate

\section{INTRODUCTION}

Ectopic pregnancy is the implantation of the embryo at any site other than the endometrial cavity. The commonest site for an ectopic pregnancy is fallopian tube $(95 \%)$. Other sites are ovary, cervix, prior cesarean scar or in the abdominal cavity $(5 \%) .{ }^{1}$ The incidence of ectopic pregnancy is $1-2 \%$ of all pregnancies (Barnhart). ${ }^{2}$ With major improvements in diagnostic methods such as serum pregnancy tests and high resolution trans vaginal ultrasonography, it is now possible to make an early diagnosis of an ectopic pregnancy. The time prior to rupture is being utilized to target the rapidly dividing embryo with cytotoxic drugs. The scenario has changed from the life-threatening presentation requiring urgent surgery to asymptomatic women being managed with non-surgical options. The non-surgical options include expectant management and medical management using methotrexate in single or multi dose regimens. Transvaginal ultrasound guided local injection is also described as an alternative therapy but mostly used for cervical, cornual or advanced, live ectopic pregnancies. ${ }^{3}$

Medical management of an unruptured ectopic pregnancy with intramuscular methotrexate in carefully selected patients offers success rates comparable to surgery, is cost effective, avoids inherent morbidity of anaesthesia and moreover promises no loss in future fertility potential. ${ }^{4}$ Methotrexate, a folic acid antagonist can be administered systemically using single dose method at lower levels of HCG or be given in a multidose regimen at higher HCG levels. ${ }^{5}$

The purpose of this study was to ascertain the efficacy of single dose method of MTx in carefully selected patients with unruptured tubal ectopic pregnancy. 


\section{METHODS}

This was an observational prospective study conducted at a tertiary care hospital with facilities of a laparoscopic surgical unit in an emergency setting. We followed the ACOG recommendations (level B) for selecting the patients for this study. ${ }^{5}$ The study included patients admitted during the study period of June 2014 to May 2017 with an ectopic pregnancy.

Baseline investigation comprising of complete blood count, blood group and $\mathrm{Rh}$ factor, renal and liver function tests were done apart from HCG levels and transvaginal sonography.

\section{Inclusion criteria for initiating methotrexate therapy}

- Hemodynamic stability

- Extraovarian adnexal mass less than $4.0 \mathrm{~cm}$

- No history of severe or persistent abdominal pain

- Hemoperitoneum $<100 \mathrm{ml}$

- Absent cardiac activity.

\section{Exclusion criteria for systemic Methotrexate}

- Intrauterine pregnancy

- Evidence of immunodeficiency

- Moderate to severe anemia

- Leucopenia (leukocytes $<2000$ cells $/ \mathrm{mm}^{3}$ )

- Thrombocytopenia (platelets $<100,000$ )

- $\quad$ Sensitivity to MTx

- Active pulmonary disease

- Active peptic ulcer disease

- Clinically important hepatic or renal dysfunction

- Adnexal mass size $>4 \mathrm{~cm}$

- Beta HCG levels $>5000$ initial

Patients who fulfilled the above criteria were included in the study group. They were informed about possibility of tubal rupture, need for surgery, failure of treatment and need for Blood transfusion. Informed consent was taken prior to administering Methotrexate.

Single dose regimen was started for all patients in the study group. ${ }^{5}$ Methotrexate was given as an intramuscular injection in a dose of $50 \mathrm{mg} / \mathrm{m}^{2}$ body surface area. The day of first dose of injection was considered as day 1 . Beta HCG levels were repeated on day 4 and day 7 after giving the injection. Patients were instructed to avoid intercourse, folic acid supplements till completion of treatment. Blood grouping was done, and injection AntiD 50 micrograms was given accordingly.

A decline of $15 \%$ or more in HCG levels between day 4 and day 7 was considered adequate. Patient was followed up with weekly HCG levels until a negative value was reached. For those who did not register a fall of $15 \%$ between day 4 and day 7, a second dose of Methotrexate was given. And the same sequence was followed.
Subsequent decline in beta HCG level to $5 \mathrm{mIU} / \mathrm{ml}$ with one or two doses were considered as successful. An inadequate fall in beta HCG after second dose or signs of tubal rupture, hemodynamic instability was considered as failure of medical management and surgical intervention was done. Any major or minor side effects were noted.

\section{Statistical analysis}

Data were described in terms of range; mean \pm standard deviation $( \pm \mathrm{SD})$, median, frequencies (number of cases) and relative frequencies (percentages) as appropriate. Comparison of quantitative variables was done using ANOVA. A probability value ( $\mathrm{p}$ value) less than 0.05 was considered statistically significant. All statistical calculations were done using SPSS (Statistical Package for the Social Science) SPSS 17 version statistical program for Microsoft Window.

\section{RESULTS}

In the 36-month study, a total of 171 patients with an ectopic pregnancy were managed at this hospital. Two of these were non-tubal pregnancies and one was a heterotopic pregnancy after an ART procedure. These three patients were excluded. In 131 pregnancies rupture was documented at the time of presentation and had primary surgical management. A total of 37 pregnancies were unruptured tubal pregnancies who were considered for medical management with methotrexate. Five were again excluded because of high HCG levels or large adnexal mass size. None of the patients was suitable for expectant management (HCG levels less than 200 $\mathrm{mIU} / \mathrm{ml})$. One more patient was excluded in view of thrombocytopenia. All 31 patients who fulfilled the criteria agreed for the medical management and are included in the final analysis (Figure 1).

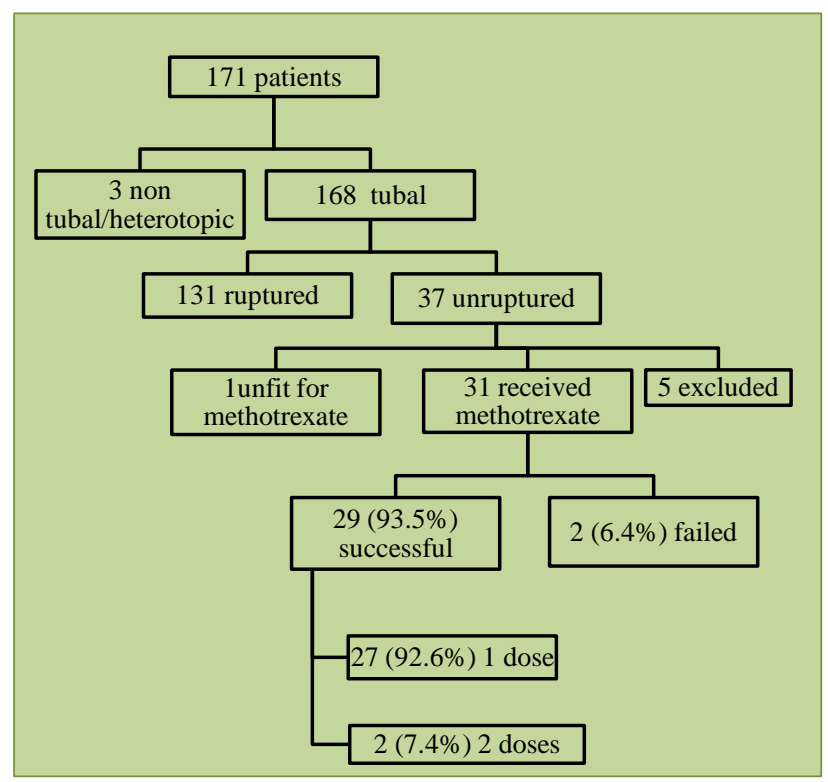

Figure 1: Sequence of patient recruitment for the study. 
Seventeen $(54.83 \%)$ patients were nulliparous and 14 (45.16\%) were parous. Two patients had a past history of ectopic pregnancy. A total of 12 patients $(38.7 \%)$ were undergoing treatment for infertility at our centre or outside. 15 patients $(48 \%)$ presented with amenorrhea and pain lower abdomen. 13 patients $(42 \%)$ presented with amenorrhea followed by bleeding. Only 3 patients (9.6\%) presented with amenorrhea and USG finding of adnexal mass. The initial size of the hematosalpinx was between $1-2 \mathrm{~cm}$ in only 3 of the patients $(9.6 \%)$. Maximum no. of patients (17) (54.84\%) had a size of 2-3 cm. 11 patients $(35.48 \%)$ had a hematosalpinx of size $3-4$ $\mathrm{cm}$.

For the purpose of analysis, patients were divided into three groups. Group 1 included patients with successful outcome with single dose of methotrexate. Group 2 patients had a successful outcome with two doses of the drug. Group 3 was of those patients who had failure of treatment with the drug. Table 1 shows the comparison of various parameters of the three groups.

Table 1: Comparison of various parameters between single dose, two dose and unsuccessful groups.

\begin{tabular}{|c|c|c|c|c|c|c|c|c|c|c|c|}
\hline & $\begin{array}{l}\text { One } \\
\text { Dose }\end{array}$ & & & & successfu & F & & & & $\begin{array}{l}1 \text { dose vs } \\
\text { un- } \\
\text { successful }\end{array}$ & $\begin{array}{l}2 \text { dose vs } \\
\text { un- } \\
\text { successful }\end{array}$ \\
\hline & Mean & SD & Mean & SD & Mean & Sd & & & $\begin{array}{l}P \\
\text { value }\end{array}$ & $\begin{array}{ll} & P \\
\text { e } & \text { value }\end{array}$ & $\begin{array}{l}P \\
\text { value }\end{array}$ \\
\hline $\begin{array}{l}\text { Gestational } \\
\text { age }\end{array}$ & 40.30 & 2.35 & 42.00 & 0.00 & 41.50 & 3.54 & 0.683 & 0.514 & 0.333 & 0.492 & 0.834 \\
\hline Size & 2.64 & 0.54 & 3.55 & 0.49 & 3.30 & 0.99 & 3.512 & 0.044 & 0.035 & 0.120 & 0.657 \\
\hline Age & 27.44 & 3.83 & 26.50 & 0.71 & 34.00 & 2.83 & 3.010 & 0.065 & 0.732 & 0.023 & 0.054 \\
\hline Day1 & 1980.89 & 843.08 & 4710.50 & 43.13 & 3872.00 & 1541.49 & 12.953 & 0.000 & 0.000 & 0.006 & 0.340 \\
\hline Day 4 & 1516.63 & 1025.88 & 6972.00 & 67.88 & 5877.00 & 2282.54 & 36.578 & 0.000 & 0.000 & 0.000 & 0.319 \\
\hline Day 7 & 630.26 & 863.37 & 6604.00 & 8.49 & & & 92.572 & 0.000 & & & \\
\hline Day 14 & 180.33 & 421.41 & 2952.00 & 350.72 & & & 81.476 & 0.000 & & & \\
\hline
\end{tabular}

Treatment with methotrexate was successful in 29 $(93.5 \%)$ patients. 27 out of $29(93 \%)$ needed a single dose of methotrexate and 2 out of $29(7 \%)$ needed 2 doses of methotrexate. Both the patients received second dose in view of moderate fall $(<15 \%$ difference between day 4 and7) in HCG levels on day 7. Reason for surgical management in both the failed patients was appearance of excessive abdominal pain and free fluid on USG.

The patients who required one dose were slightly younger than the ones who were failures of treatment, $\mathrm{p}<0.05$. The patients who required two doses had marginally bigger hematosalpinx ( $\mathrm{p}$ value 0.044). In the successful patients the average time for HCG levels to become negative was 27.3 days in single dose patients and 46.9 days in 2 dose group (a delay of about 19.6 days). Day 4 HCG levels fell in 21 patients $(67.7 \%)$ as compared to day 1. None of these patients had failure or needed a second dose. Day 4 HCG levels were more than day 1 levels in 10 patients $(32.2 \%)$. Two of these patients had failure and 2 of them needed a second dose. None of the patients with adnexal mass of size less than $2.5 \mathrm{~cm}$ had a failure. Both failures were in patients with size of ectopic pregnancy more than $2.5 \mathrm{~cm}$. There were no serious adverse events during the study.

\section{DISCUSSION}

Ectopic pregnancy is a common diagnosis in the obstetric emergency room. As is the current scenario at our hospital, most of our patients arrived at the hospital with signs and symptoms of a ruptured ectopic pregnancy $131 / 171(76.6 \%)$ and received primary surgical treatment. After further exclusions, only $19.2 \%$ of the total ectopic pregnancies could be offered medical management plan. In contrast in a study by Talwar, $74.4 \%$ could be offered medical treatment. This was probably because most of these patients were undergoing IVF and were on close follow up. ${ }^{6}$ In another study by Vaswani, $54.6 \%$ patients had primary surgery and in the study by Bonin, $57.2 \%$ patients were treated with primary surgical therapy. ${ }^{7,8}$ These figures are comparable to our study. Delay in first visit to doctor after pregnancy confirmation is probably the reason for the higher percentage of ruptured ectopic pregnancy in this part of North India.

Success rate of medical management of ectopic pregnancy with methotrexate has been evaluated in many studies. We documented an overall success rate of $93 \%$ with single dose methotrexate protocol.

Various similar studies documented success rates between $75 \%$ by Vaswani, $78.5 \%$ (314/400) by Bonin, $77.1 \%(285 / 370)$ by Mirbolouk to better rates by Bottin, $89 \%$ overall (91 patients) and Orozco $88 \%$ (126 total). ${ }^{7-11}$ These studies vary widely in-patient selection and cut offs for HCG values (10,000 or more) and dose protocols (single dose versus multidose). Present study had more strict criteria for patient selection compared to these studies, which may have contributed to better outcomes. 
Nonetheless, initial serum HCG level has been found to be the best prognostic indicator of success. Lipscomb, in a study on 350 patients found a success rate of $94 \%$ when HCG level was below $10,000 \mathrm{mIU} / \mathrm{ml}$ and success rate fell to $75 \%$ with HCG level more than $10,000 \mathrm{mIU} / \mathrm{ml}^{12}$ As initial HCG level increases, success declines. We still don't have a single value which can be a recommendation for delivering a near $100 \%$ success rate. ${ }^{13}$

In the present study, the initial HCG level in success group (1 dose) was significantly lower as compared to two dose group and unsuccessful group (Table 1). Similar results were documented in various studies by Vaswani, Bonin, Potter and Ustunyurt. ${ }^{7,8,14,15}$ There was an average fall in Day 4 HCG levels in one dose group as compared to two dose or unsuccessful group where a rise was documented. This was also observed in some similar studies. $^{7-9,12}$

All patients in whom HCG level fell on Day 4 had a success with single dose of methotrexate. This parameter can be considered as a very good indicator of success later. Similar findings were published by Nyugen. ${ }^{16}$

There was no significance difference between groups regarding gravidity and gestational age at presentation. Mirboulouk reported similar results. ${ }^{9}$

\section{CONCLUSION}

Carefully selected patients of unruptured ectopic pregnancy can be safely and successfully treated with systemic methotrexate. Fall in HCG levels on Day 4 of treatment is a good predictor of success.

\section{Funding: No funding sources}

Conflict of interest: None declared

Ethical approval: The study was approved by the Institutional Ethics Committee

\section{REFERENCES}

1. Varma R, Gupta J. Tubal ectopic pregnancy. BMJ Clin Evid. 2009:1406

2. Barnhart KT. Ectopic pregnancy. N Engl J Med. 2009;361(4):379-87.

3. Monteagudo A, Tarricone NJ, Timor-Tritsch IE, Lerner JP. Successful transvaginal ultrasound guided puncture and injection of a cervical pregnancy in a patient with simultaneous intrauterine pregnancy and a history of a previous cervical pregnancy. Ultrasound Obstet Gynecol. 1996;8:381-6.

4. Barnhart KT, Esposito M, Conifaris C. An update on the medical management of ectopic pregnancy. Obstet Gynecol Clin North Am. 2000;27:653-67.
5. ACOG Practice Bulletin No. 94: Medical Management of ectopic pregnancy. Obstet Gynecol. June 2008;111(6):1479-85.

6. Talwar P, Sandeep K, Naredi N, Duggal BS, Jose T. Systemic methotrexate: An effective alternative to surgery for management of unruptured ectopic pregnancy. Med J Armed Forces India. 2013;69(2):1303 .

7. Vaswani PR. Predictors of success of medical management of ectopic pregnancy in a tertiary care Hospital in United Arab Emirates. J Clin Diagn Res. 2014;8(8):OCO4-8.

8. Bonin L, Pedreiro C, Moret S, Chene G, Gaucherand P, Lamblin G. Predictive factors for the methotrexate treatment outcome in ectopic pregnancy: a comparative study of 400 cases. European J Obs Gyne Rep Biol. 2017;208:23-30.

9. Mirbolouk F, Yousefneznad A, Ghanbari A. Predicting factors of medical treatment success with single dose methotrexate in tubal ectopic pregnancy: a retrospective study. Iran J Reprod Med. 2015;13(6):351-4.

10. Bottin P, Gnisci A, Crochet P, Butzback P, Cravello L, Gamere $M$, et al. Prognostic value of early HCG changes after methotrexate injection for Ectopic pregnancy. Gynecol Obstet Fertil. 2014;42:3-7.

11. Orozco EM, Sanchez-Duran MA, Bello-Munoz JC, Sagata J, Carreras E, Roura LC. BHCG and prediction of therapeutic success in ectopic pregnancies treated with methotrexate, results from a prospective observational study. J Matern Fetal Neonatal Med. 2014;30:1-5

12. Lipscomb GH, Mc Cord ML, Stovall TG, Huff G, Portera SG, Ling FW. Predictors of success of methotrexate treatment in women with tubal ectopic pregnancies. N Engl J Med. 1999;341:1974-9.

13. ACOG Practice Bulletin No. 191 Summary: Tubal Ectopic Pregnancy. Obstet Gynecol. 2018;131(2):40911.

14. Potter MB, Lepine LA, Jamieson DJ. Predictors of success with methotrexate treatment of tubal ectopic pregnancy at Grady Memorial hospital. Am J Obstet Gynecol. 2003;188:1192-4.

15. Ustunyurt E, Duran M, Coskun E, Ustunyurt OB, Simsek H. Role of initial and day 4 human chorionic gonadotropin levels in predicting the outcome of singledose methotrexate treatment in women with tubal ectopic pregnancy. Arch Gynecol Obstet. 2013;288;1149-52.

16. Nguyen Q, Kapitz M, Downes K, Silva C. Are early human chorionic gonadotropin levels after Methotrexate therapy a predictor of response in ectopic pregnancy? Am J Obstet Gynecol. 2010;202:630-5.

Cite this article as: Juneja SK, Jain K. Success of medical management of tubal ectopic pregnancy with Methotrexate in a tertiary hospital in North India. Int J Reprod Contracept Obstet Gynecol 2018;7:2377-80. 